\title{
Os grupos na atenção básica de saúde de Porto Alegre: usos e modos de intervenção terapêutica
}

\author{
Groups in basic health attention in Porto Alegre: \\ uses and forms of therapeutic intervention
}

Rosana M affacciolli ${ }^{1}$

M arta Julia M arques Lopes ${ }^{2}$

${ }^{1}$ Faculdade deEnfermagem, Centro Universitário IPA M etodista. Rua Guilherme Alves 715/205, Jardim Botânico. 90680-001 Porto Alegre RS.

rosanamaffac@yahoo.com.br

${ }^{2}$ Escola de Enfermagem,

UniversidadeFederal do

Rio Grande do Sul.
Abstract This article deals with groups as an assistential modality used by the services of basic health attention. Workshops, health education groups, as well as, lectures are different activities done in relation to other traditional attendances. The study that is behind this discussion had as its main aim to know the profile of assistance, under groups' organization, offered in the U nits which make part of the Basic Health Network in Porto Alegre. Within a total of 124 health services, 116 professionals were approached, among them, 96 developed groups. We could verify that the groups have therapeutic relevance because they favor the sharing of information and the learning about aspects which are related to the topic health-sickness. They constitute inclusive practices, which are able to create a link with the users and the service, as well as, to reformulate the existing assistential model. Therefore, it was verified that the understanding of these practices reflects on its dimension of the group assistance qualification and also the strategic dimension of compensation in the attendance of the increasing demand of health.

Key words Basic health services, Group practice, Strategies
Resumo Esse artigo trata dos grupos como modalidade assistencial utilizada pelos serviços de atenção básica de saúde. O ficinas, grupos de educação em saúde e palestras constituem atividades diferenciadas em relação aos demais atendimentos tradicionais. 0 estudo que subsidia essa discussão teve como objetivo conhecer o perfil da assistência, sob a forma de grupos, prestada nas unidades que compõem a rede básica de saúde de Porto A legre. Foram abordados 116 profissionais, deum total de 124 serviços de saúde, entreosquais 96 desenvolviam grupos. Evidenciou-se que os mesmos têm relevância terapêutica por favorecerem a troca de informações eo aprendizado sobre aspectos relacionados à saúde/doença. Constituem práticas inclusivas, capazes de vincular os usuários aos serviços e de reformular o modelo assistencial vigente. Assim, constatou-se que a compreensão dessas práticas remete a sua dimensão de qualificação da assistência col etiva etambém a uma dimensão estratégica de compensação deatendimento às crescentes demandas de saúde. Palavras-chave Serviços básicos de saúde, Prática de grupo, Estratégias 


\section{Introdução}

O bservando-se a assistência em saúde prestada no âmbito da atenção básica, constata-se que as atividades degrupo eações de saúde, geral mente organizadas de acordo com demandas programáticas, são cada vez mais atuais e frequentes. Assim, as modalidades se diversificam para atender usuários hipertensos, diabéticos, mulheres, gestantes, idosos, entreoutros, no sentido deatuar na complementaridade terapêutica.

É fato a escassez deelementos indicativos para se conhecer o cenário em que essas atividades se apresentam, tampouco as condições em que se desenvolvem equanto a sua efetividade. No município de Porto Alegre, as atividades de grupo estão em franca implementação, representando um tipo de assistência em evidência nos serviços básicos de saúde. Esteestudo propôs-se, então, a traçar um perfil da assistência prestada nas unidades de saúde que compõem essa rede, com enfoque específico nessas práticas ${ }^{1}$.

Um dos pontos que chamou a atenção referese à falta de fundamentos teóricos e meios administrativos reguladores dessas práticas, que as tornam completamente distintas nos locais em que acontecem. No caso dos grupos na rede básica de saúde de Porto Alegre, há uma certa banalização dessas atividades, tornando-as mais sujeitas a situações desfavorecedoras. De fato, não se pode considerar qualquer totalidade/coesão de pessoas nesses processos e que, nessa lógica, sejam consideradas um grupo. Uma certa horizontalidade, um ajuste mútuo de ideias e pensamentoséimprescindível econstitui a maneira do grupo expressar-se como um todo, desde que todos se sintam pertencentes à total idade grupal ${ }^{2}$.

Assim, deparou-se com informações que davam conta dareal efetividade das atividades degrupo como assistência resolutiva, mas também se pôde visualizar sua utilidade para responder ao elevado número de procura por atendimentos, configurando-se em uma estratégia de demanda.

Por outro lado, constata-se que a potencialidadeterapêutica existee repousa na possibilidade de promover saúde e educação em contextos que permitem "a articulação entre saberes técnicos e populares e a mobilização de recursos institucionais e comunitários para o enfrentamento dos problemas de saúde" ${ }^{3}$, além de resgatar elementos capazes de implementar a integralidade na assistência, melhorando também as relações entre profissionais e usuários dos serviços. 0 dina- mismo que envolve os grupos, considerando as teorizações da promoção e educação à saúde, pode representar alternativa operacional necessária para a afirmação desses preceitos na prática. Acredita-se que são instrumentais metodológicos eficazes, capazes de viabilizar, por meio do vínculo entre os participantes, e desses com a estrutura institucional, a compreensão das situações de vida, saúde edoença, sendo incorporados aspectos importantes que fundamentarão certos comportamentos para a promoção da saúde.

Dentre as estratégias de educação em saúde, foi possível evidenciar as atividades degrupo como uma forma de sistematizar a assistência. Já sua funcionalidade estaria atrelada, além dos aspectos de tratamento, a uma forma de manejar o elevado número de procura por atendimentos, excluindo dos mesmos os chamados agravos externos e/ou atendimentos deurgência/emergência.

De outro modo, as atividades educativas, e nesse contexto, os grupos, podem servir para amenizar a dominação exercida pel os serviços de saúde que, apesar de manterem como meta a difusão de informações que contribuam para a melhoria da qualidade de vida, limitam-seà transferência de informações para a população sobre determinados procedimentos, com caráter coercitivo e traços de autoridade e prescrição ${ }^{4}$.

Um outro ponto a considerar é o cenário da atenção básica em saúde, tal como se apresenta. M esmo com as inovações no que se refere aos model os assistenciais, muitas vezes a potencialidade de uma atividade assistencial inovadora é revertida em favor de formas clássicas de atendimento esuas concepções estagnantes. Essas compreendem, principalmente, ações programáticas planejadas em torno do núcleo da assistência médica, pressupondo um agir centrado em uma única categoria profissional ${ }^{5}$.

Pensa-se que as reflexões concernentes aos dados desta pesquisa historiam as atividades de grupo e suas evidências se tornam válidas para um olhar a médio e longo prazo sobre as práticas assistenciais na atenção básica de saúde. Os achados destacados neste artigo são resultantes do empenho em investigar a organização da rede básica de saúde de Porto Alegre, destacando a prática de atividades de grupo, nesses serviços. A partir desses dados e tecendo as análises pertinentes, tentou-se complementar, por intermédio do diagnóstico situacional, o conhecimento singularizado acerca dessa temática. 


\section{Objetivos}

Teve-se como objetivo geral conhecer o perfil da assistência prestada nas unidades que compõem a rede básica de saúde de Porto Alegre, com enfoque nas atividades de grupo. Dessa forma, emergiram objetivos específicos da problemática apresentada: mapear as unidades de saúde componentes da rede básica de Porto Alegre; identificar as unidades que incluem atividades de grupo no processo de trabal ho e em que circunstâncias há implantação dessas práticas; refletir sobre as práticas adotadas nesses serviços e as abordagens metodológicas que as embasam e analisar aspectos relativos à incorporação dessas práticas na reconfiguração da proposta assistencial na atenção básica à saúde do município de Porto Alegre.

\section{Metodologia}

Com o objetivo de explorar para conhecer a organização das atividades de grupo nos seus locais deimplantação, utilizaram-se métodos e técnicas de estudo que contemplaram amplamente as nuances intervenientes neste tipo de investigação. Portanto, a configuração éa de um estudo exploratório que descreve e analisa o objeto em suas dimensões quantiqualitativas, no sentido de investigar seu perfil e, principalmente, as formas de compreensão estabelecidas pelos atores responsáveis pela implementação das atividades de grupo. A abordagem quantitativa forneceu indícios numéricos, servindo como su porte para as reflexões sobre o perfil dessa atividade assistencial, constituindo-se de dados como distribuição, diversidade da clientela atendida, de trabalhadores envolvidos e heterogeneidade das práticas.

O campo de estudo foi composto pelas 124 unidades básicas de saúde de Porto Alegre, até então, em funcionamento. As características variam conforme a tipologia das unidades, com a vigência do Programa de Saúde da Família até Centros de Saúde, onde se dá, entre outros atendimentos, a realização de procedimentos cirúrgicos de menor complexidade.

Como sujeitos participantes, teve-se a contribuição de 116 profissionais de diferentes áreas da saúde, correspondendo a um profissional entrevistado por serviço. A inclusão dos mesmos como participantes obedecia ao critério de atuarem nas atividades de grupo e de conhecerem a sistemática desse atendimento. A todos foi apresentado um termo de consentimento informado, o qual seria assinado, momento em que se destacou o caráter não obrigatório quanto à participação na pesquisa e os procedimentos utilizados. Também o projeto foi submetido aos Comitês de Ética em Pesquisa pertinentes ao campo (ComitêdeÉtica da Secretaria M unicipal deSaúde de Porto AlegreeComitê deÉtica em Pesquisa do Grupo H ospitalar Concei ção), respeitando os preceitos da Resolução no 196/1996 do Consel ho Nacional de Saúde.

As informações geradas foram coletadas entre julho e outubro de 2005, por meio de um formulário composto de questões abertas e fechadas. As entrevistas foram marcadas por telefone e procurou-se traçar um roteiro de visitas em que se poderia abordar as unidades pertencentes ao entorno das quejá haviam sido confirmadas, mas que não haviam sido contatadas previamente. Assim, foi possível otimizar o tempo e acessar mais rapidamente a totalidade de unidades alvo do estudo.

As informações geradas a partir dos dados demográficos e quantitativos foram apresentadas sob a forma descritiva através de frequência simples e percentuais em tabelas e gráficos. Do total de entrevistas, 22 foram gravadas e transcritas, procurando-se contemplar profissionais de diferentes áreas.

\section{Resultados}

O perfil dos serviços e dos trabalhadores

$N$ as diretrizes da lei pela qual ér regulamentada a Saúde no Brasil - Sistema Único de Saúde (SUS) - encontra-se, em uma de suas instâncias, a operacionalização do sistema de saúde de forma regionalizada e hierarquizada, buscando, com isso, uma descentralização político-administrativa no que se refere a esse sistema ${ }^{6}$. Nesse âmbito, a atenção básica representa o principal meio pelo qual a população em geral acessa 0 sistema de saúde, sendo composta por unidades básicas de saúde. Essas são espaços alocados de maneira a cobrir todo o território de uma esfera política municipal, conforme os conceitos da descentralização/municipalização da saúde ocorrida nos anos noventa no Brasil ${ }^{7}$.

Nessa perspectiva, o que se contatou foram serviços de saúde que se apresentavam organizados territorialmente, de modo a cobrir toda a área do município eatender os usuáriospor meio do critério da adscrição, o que confere 0 acesso restringido conformelocal demoradia. Também, como se poderia inferir, a tendência é a oferta de 
unidades de pequeno porte e com atendimentos de menor complexidade. A Estratégia de Saúde da Família aparece de maneira substancial, corroborando a ideologia governamental de estratégia para reorganização da atenção básica no Brasil, de acordo com a legislação do SU S.

A distribuição das equipes varia, principalmente, conforme $o$ tipo de atendimento ofertado. Verificou-se a tendência da organização do trabalho de maneira multidisciplinar, tanto nas equipes ditas básicas, compostas de enfermeiras, médicos, auxiliares de enfermagem eagentes comunitários de saúde (ACS), como nas equipes "especializadas", compostas também por médicos especialistas, cirurgiões-dentistas (eassistentes de nível médio), nutricionistas, psicólogos, assistentes sociais e terapeutas ocupacionais.

As atividades de grupo: modos e usos

Ao acessar essas unidades, um ponto controverso da abordagem foi a denominação a ser utilizada para explanar o que seriam esses grupos, já que tratava justamente desse tipo deatendimento.

No panorama da saúde, pode-se dizer que a composição atual das estratégias de grupos, utilizadas pelos serviços de saúde, foi influenciada por intervenções psicoterapêuticas grupais, a partir dos anos vinte. Há registros dessa modalidade assistencial em literatura científica, ultrapassando cem anos atrás, podendo-se identificar alguns marcos importantes, como o surgimento de organizações que se tornaram muito conhecidas com o uso detécnicas grupais, dentre elas, a dos "Alcoólicos Anônimos", iniciando sua atuação a partir de 1935. Desde então, a maioria das publicações científicas sobre grupos advém desse período e reúne uma série de estudiosos, em grande parte psicanalistas, como Jacob L. Moreno, Kurt Lewin (psicólogo), Foulkes, Pichón-Rivièree Bion? ${ }^{9}$.

Estudando a evolução histórica quanto ao surgimento dos grupos psicoterápicos, afirmaseque"diversas técnicas desta modalidade de tratamento têm sido desenvolvidas para atendimento depopulações específicas de pacientes, com as mais diversas condições médicas e psicossociais" ${ }^{\prime \prime}$. Joseph H. Pratt e Jacob Levy M oreno, tendo como foco a psiquiatria, foram os precursores da psicoterapia de grupo, tendo se dedicado aos estudos e participado do enriquecimento dessas técnicas. 0 crescimento do emprego desse método em psiquiatria decorreu na década de vinte, particularmente em pacientes internados, sendo, inicialmente, classificado como tratamento ou instrução em massa, aula e terapia coletiva ${ }^{10}$.

Associando-os à realidade encontrada nos serviços de saúde, o movimento dessa modalidade de tratamento expandiu e tende a prosperar para além do atendimento de pacientes psiquiátricos, internados e não internados, no setor público e privado. A relevância também está na assistência a doentes de diversas condiç̧̃̃es de saúde, atendidos em âmbito ambulatorial ou hospitalar, assim como à população em geral, assistida por organizações comunitárias de autoajuda ${ }^{10}$.

Avançando nessa análise, é válido resgatar duas classificações gerais, encontradas em literatura específica: grupos operativos e grupos psicoterápicos. N esse caso, a técnica de grupo operativo centraliza-se em uma tarefa proposta em nível consciente, ou seja, "somente nas situações em que fatores inconscientes inter-relacionais ameaçarem a integração ou evolução exitosa do grupo, é que caberão eventuais intervenções de ordem interpretativa". Quanto às finalidades, esse tipo de grupo cobre quatro diferentes campos de atuação que podem, por vezes, interpor suas características: ensino-aprendizagem (treinamento, reflexão); institucionais (escolas, associações declasse, sindicatos, igrejas); comunitários (grupos de gestantes, crianças, pais, líderes comunitários) e terapêuticos (situações patológicas orgânicas) ${ }^{11}$.

Os grupos operativos contribuem com um importanteaporte conceitual teórico, a partir das ideias do seu maior mentor - Enrique PichónRivière. Esse psicanalista argentino elaborou um conceito de grupo a partir de suas observações com pacientes hospitalizados. N esse contexto, identificou as características do processo grupal, delimitando três momentos da tarefa ou do objetivo grupal: a prétarefa, a tarefa e o projeto são momentos que se apresentam em uma sucessão evolutiva e sua aparição e interjogo constante podem situar-se diante de cada situação ou tarefa que envolva modificações no sujeito ${ }^{12}$.

Outras concepções indicam ainda que o grupo é construído em meio a um movimento que vai da serialidade à grupalidade. $\mathrm{Na}$ serialidade (série de pessoas), há objetivos em comum; porém, cada um está centrado em suas próprias necessidades. Avança-se para a grupalidade, quando as necessidades tornam-se comuns a todos e as pessoas se articulam para concretizar esses objetivos. Os autores referem ainda que essa passagem ocorreem torno da noção de "tarefa" (resgatada dos conceitos de Pichón-Rivière); o grupo desenvolve em conjunto eimplica vínculos deintensa reciprocidade entre seus integrantes ${ }^{13}$. 
Perpassando esses pressupostos, considerase que o uso da expressão grupos é carregado de um aporte teórico que deve ser levado em consideração quando da sua menção nas ações terapêuticas. Portanto, no âmbito desta pesquisa, um dado esboçava-se interessante para uma análise inicial: qual a denominação que os profissionais de saúde utilizam ao se referir a essas atividades? Prontamente, 98\% mencionaram que se tratava degrupos. Somenteem doislocais foram mencionadas nomenclaturas diferentes, sendo consideradas oficinas eencontros. Contudo, écomum a menção de outros termos para se referir a essas atividades, como consulta coletiva, aulas, palestras, cursos, o que denota, de certa forma, suas diversas finalidades.

Independentemente da nomenclatura, o que se pôde constatar é que essa sistemática de atendimento é largamente utilizada pelas unidades de saúde. Das 124 unidades que compõem a rede deatenção básica de Porto Alegre, 116 foram alvo desta pesquisa e constatou-se a existência de atividades dessa natureza em 96 unidades, o que corresponde a $83 \%$ do total de unidades pesquisadas. Outra constatação é que não houve distinção significativa quanto à realização de atividades de grupo nos serviços componentes da rede, podendo-se observar que eram atividades presentes em diferentes arranjos institucionais.

Em relação aos profissionaisqueatuavam com os grupos, a informação referida era de que muitos já haviam tido algum tempo de experiência em áreas fechadas de assistência, como em hospitais. Isso remetea pensar como acontecea adequação/qualificação para se envolverem com os diferentes processos e práticas na saúde coletiva. Torna-se interessante, então, tentar entender como esses profissionais se organizam para esse trabaIho, em função das suas condutas particulares, dos processose relações detrabalho. Um dosachados desta pesquisa refere-se novamente à discussão sobre a organização multidisciplinar da assistência, na medida em que quase $50 \%$ dos entrevistados referiram o desenvolvimento de atividades de grupo com participação multiprofissional.

No entanto, se fazia necessário o questionamento sobre quais profissionais eram coordenadores ou responsáveis pelas atividades de grupo nas unidades pesquisadas. Diante da variabilidade de respostas e das incertezas dos entrevistados sobre o que poderia corresponder a uma coordenação dessas atividades, resolveu-sequestionar qual o envolvimento dos profissionais de saúde e sua definição como coordenadores, palestrantes, idealizadores, ajudantes ou outras de- nominações particulares que expressassem essa participação. Dessa forma, como já mencionado, em muitos dos serviços onde eram realizadas atividades de grupo, constava a participação de equipes multiprofissionais. Poder-se-ia depreender que todos os trabalhadores de saúde do serviço em questão atuariam junto aos grupos. Contudo, cabe ressaltar, para fins de sistematização, que ao serem consideradas as falas dos participantes, explorou-sequem participaria nesta categoria de classificação. Assim, equipe multiprofissional designa todos ou a maioria dos profissionais de saúde do serviço, atuando nos grupos, direta ou indiretamente, incluindo os profissionais de nível médio e os agentes comunitários de saúde.

Identificaram-se especificidades quanto à questão da coordenação das atividades, principalmente no que se refere à organização do trabalho eàs competências profissionais, como está sendo explicitado nesta fala: "Toda a equipe de saúde participa, mas tem um coordenador, né. Por exemplo, no grupo dehipertensos, quando tem que falar de saúdeda mulher, então se convida um profissional mais próximo da saúde da mulher, daí (neste mesmo grupo) a gente sempre faz um encontro sobre saúde bucal, daí a gente chama o pessoal da odonto e aí a gente faz com essa composição, mas sempre tem um profissional que coordena." (E-1)

Quanto à participação dos ACS, considerando que esse trabalhador foi integrado recentemente às equipes de saúde com 0 advento da Estratégia de Saúde da Família, são necessários alguns esclarecimentos. Para fins de contratação, a esses trabal hadores não foram feitas exigências quanto à formação específica na área da saúde, mas sim de serem moradores da área adscrita da unidade, além de outros requisitos mínimos. M esmo assim, pôde-se encontrar, em uma unidade, ACS atuantes nas atividades de grupo sem apoio de outros profissionais. 0 que habitualmenteacontece, podeser evidenciado na fala que segue: "O responsável por todos os gruposéa doutora. [P: e quem são as pessoas que estão sempre presentes?] . É os agentes comunitários de saúde. Somos nós que formulamos, buscamos todas as informações pra essegrupo, do hipertenso, geral mente é sempre a doutora que faz a palestra, que é mais ligado à área dela. A enfermeira participa do de gestante enem sempre ela pode participar, fica um tempo e sai." (E-2)

Fica clara a condição de poder-saber, legitimada, muitas vezes, pela hierarquia existenteentre os profissionais denível superior, confirman- 
do sua autoridade no que se refere às condutas assistenciais. Porém, ao se tratar de atividades de grupo, aos ACS é concedida a responsabilidade de "fazêlas", quando as outras demandas do trabalho técnico - consultorias individuais, trabaIhos burocráticos - ocupam, indispensavelmente, esse tempo.

Outra face do trabalho, das diferentes categorias profissionais, aponta para um juízo de valor queédado a determinadas práticas em saúde em detrimento de outras. N esse caso, os grupos são considerados atividades secundárias, proporcionalmente sem importância diante das ações individuais ou burocráticas dos serviços. A lógica quese impõeéa de um sistema atrelado às ações curativas, à atenção individualizada efragmentada aos usuários e ao enfoque direcionado para a doença.

Essas distorções quanto aos papeis exercidos por coordenadores e/ou executores dos grupos remete a pensar sobre a capacitação do profissional para efetivar o trabalho grupal. Assim, os entrevistados foram questionados se já haviam participado de algum curso de capacitação e/ou treinamento para o trabal ho com grupos. Como resultado, 50\% citaram essas atividades realizadas tanto por iniciativas individuais como institucionais. Deste percentual, observa-se que muitas dessas capacitações $(67,5 \%)$ tiveram como foco temáticas específicas. Isso acontece com vários tipos de demandas, podendo-se salientar as com foco no atendimento ao tabagismo ou no planejamento familiar, sendo que, dentre esses assuntos, o curso de capacitação referido desenvolvia técnicas grupais como meio de implementar ações programáticas nas diferentes instituições a que pertencessem os capacitandos. Em outros exemplos relativos à capacitação, os entrevistados mencionaram cursos de formação geral que tratavam da temática de grupo, como cursos de especialização, residência em saúde, graduação, eventos científicos e, menos prevalentes, cursos de capacitação profissional para atuação em grupos operativos, concernentes à metodologia de EnriquePichón-Rivière.

$A$ atividade grupal atrelada à conformação programática da saúde pôdetambém ser evidenciada em um dos achados de pesquisa. Inseridas em programas desaúde, as demandas tem 0 acesso mais facilmente garantido a determinados procedimentos, condutas eaté mesmo a medicamentos. Foi constatado que aproximadamente $85 \%$ das unidades pesquisadas combinavam os grupos a outras condutas assistenciais. Isso deflagra algumas reflexões sobre a conveniência ea forma de inserção dos mesmos na rotina dos serviços. Emerge, em primeiro lugar, a discussão dos grupos como uma tática das unidades para atender coletivamente às demandas individuais de saúde; porém, isso pode estar velado ou, ao contrário, pode ser constatado explicitamente, como acontece, nestas falas: "A gora que eu come cei a coordenar, eu inverti um pouco. Antes eles obrigavam as pessoas a ficarem atéo final do grupo e faziam a distribuição da medicação, renovação das receitas e viam os exames. Agora é fei to o contrário, pra não ter esse caráter obrigatório, as pessoas quenão querem ficar, elas não ficam, porquea gente faz primeiro a verificação de sinais ea distribuição da medicação". (E 3)

"Sim, os grupos de diabéticos e hipertensos, a gente verifica a glicose a TA (tensão arterial). Aí, tu acaba discutindo no grupo também e isso é um incentivo pra eles, eles ficam se controlando entre eles. Todos têm que estar bem controlados no dia do grupo". (E 4)

A primeira fala demonstra a preocupação do profissional em dissociar das atividades de grupo as condutas assistenciais individuais, pretendendo, com isso, valorizar as particularidades do encontro em si - as orientações, esclarecimentos de dúvidas, troca de experiências, entre outros. Essa preocupação foi verificada nas falas de outros entrevistados, podendo-se inferir que 0 entendimento dos grupos, para alguns profissionais, é deque os mesmos constituem uma ferramenta de trabalho à parte dos outros tipos de atendimentos. Entretanto, mesmo que os participantes optem por não permanecer nas reuniões, o fato de marcarem os encontros associados à distribuição da medicação serve à unidade de saúde para atender coletivamente à demanda para o recebimento de medicações e realização de procedimentos (sinais vitais).

A fala subsequente demonstra a valorização das atividades de grupo como ocasiões a serem aproveitadas de duas maneiras: verificação de sinais e explanação sobre o significado dos mesmos aos participantes. A intenção, nesse caso, é incutir a percepção da estabilidade sintomatológicano comportamento dos participantese, consequentemente, perpetuar esse aspecto ao longo dos encontros, fazendo com que todos estejam sempre "controlados" quanto aos sintomas das doenças que os afetam.

A questão dos atendimentos coletivos de de mandas individuais, em se tratando da prática de grupos, foi uma constatação preponderante neste estudo. Portanto, a indagação pertinente a se fazer é de quais demandas individuais está se falando? 
Seria importante situar para quais finalidades ou para qual população as atividades de grupo são dirigidas. Eis que, preferentemente, as demandas incluídas em programas de saúde são alvo particular para o planejamento eimplementação dessas ações.

Nessesentido, nas 96 unidades em queseconstatou a realização de atividades de grupo, somaram-se, ao todo, 387 dessas atividades distribuídas entre as mesmas. Ou seja, cada uma realiza, em média, 4,03 atividades dessa natureza com diferentes enfoques. No que tange aos objetivos ou populações-alvo, pôde-se constatar que atividades de grupo, no âmbito das unidades básicas de saúde de Porto Alegre, têm uma clara menção às práticas programáticas oficiais. As mesmas são instituídas pelos níveis centrais de gestão a fim de organizar 0 atendimento à população, condicionadas pela situação de risco presente em determinadas frações populacionais (gestantes, crianças) ou, especificamente, a determinadas condições patológicas (tuberculose, asma, hipertensão, diabetes).

De fato, as atividades de grupo entraram no esquema ritualístico da rotina dos serviços. Existe uma necessidade dos mesmos trabal harem com a previsibilidade das circunstâncias e, por isso, até mesmo ações inovadoras acabam sendo influenciadas por essa antecipação, praticando, por exemplo, o esquema de atendimento de pacientes hipertensos em grupos, onde se distribui a medicação e se verifica a pressão. N esse caso, 0 objeto das atividades não é o usuário e sim a doença, que se centra na racionalidade das ações e no conhecimento científico dos profissionais de saúde. Estabelecer "como objeto do trabalho em saúde o usuário, significa conceber os aspectos subjetivos, e não somente os objetivos, que o caracterizam como sujeito social portador de aspirações, desejos e histórias de vida"14. Tomando essas noções como referenciais, tem-se um componente aliado para que se possa compreender melhor a complexidade dos sujeitos e dos coletivos aos quais são dirigidas as intervenções profissionais ${ }^{15}$.

Os grupos como espaços assistenciais: razões e reações dos atores

Os espaços assistenciais gerados pela perspectiva do trabalho com essas atividades podem ser tanto mais responsivos quanto mais promotoras forem as condições que norteiam sua implementação. Tais aspectos, pelo que foi possível inferir a partir dos dados desta pesquisa, são desprovidos de qualquer regularidade, ou seja, são dependentes dos microambientes, da postura e das relações profissionais e gerenciais/gestoras. Considera-se que, dentre esses elementos, 0 posicionamento profissional tem decisiva influência. Os espaços físicos podem ser desfavorecedores, mas 0 empenho de determinados trabalhadores, mesmo em condições impróprias, tenta fixar na rotina assistencial as atividades de grupo, tornando-as legítimas e uma atividade digna de atenção por parte da equipe, da comunidade e da esfera organizacional.

Por isso, cabia o seguintequestionamento aos entrevistados: "Porque se real iza esse tipo de atividade no serviço?" Em um primeiro momento, pretendia-se não considerar as justificativas pessoais dos entrevistados, mas isso foi ocorrendo naturalmente, o que remeteu a uma certa responsabilização dos mesmos sobre as atividades. Sendo assim, pode-se identificar, a partir das respostas, que tais abordagens inscrevem-se "empiricamente" na reconfiguração da proposta assistencial em atenção básica à saúde.

No entendimento dos entrevistados, a partir do pouco que se mencionou acerca da manipulação de demandas, pode-se concluir que, ao menos na consciência desses trabalhadores, os grupos são instrumentos educativos, reconhecendo neles o papel terapêutico potencial e de educação em saúde. Assim sendo, houve significativa referência à motivação do próprio profissional ou da equipe como justificativa para a implementação dos grupos nos seus locais de trabal ho. Outra referência, nesse sentido, foi quanto à valorização da equipe de saúde por parte da população, que remete à otimização do vínculo da mesma ao serviço. Esses aspectos inscrevem-se nas fal as destas duas enfermeiras: "Eu acho que tem muito a ver com as pessoas que trabalham aqui dentro. A genteentendequeo grupo é a solução para muitos problemas, mas tem muito a ver com essa unidade, com o profissional mesmo. Todas as pessoas envolvidas com o grupo acreditam no atendimento em grupo". (E 5)

"Eu, como enfermeira, sou a que mais puxo essa atividade. Se dependesse de outros técnicos, eu não sei se isso teria permanecido. Eu acho que 0 perfil do enfermeiro tem essa característica". (E 6)

A questão da valorização da equipe refere-se à possibilidadeda população, inseridaativamenteno processo assistencial, passar a valorizar esse momento, internalizar o que está sendo discutido, assimilar as orientações e ser multiplicadora desses conhecimentos. Em um ambienteem queo profissional de saúde senta-se ao seu lado, ouve suas 
dificuldades econstrói junto soluções simples para os seus problemas, as relações se horizontalizam e a equipe de saúde é vista como parceira.

Essas noções corroboram o princípio político ideológico da integralidade do cuidado, queéevidenciado em vários níveis de discussões edas práticas na área de saúde e alicerçado em um novo paradigma, no qual se está preparado para ouvir, entender e, a partir daí, atender às demandas e necessidades das pessoas, grupos e col etividades ${ }^{16}$.

A referência ao papel do enfermeiro nas atividades de grupo faz resgatar algumas considerações que evidenciam a estreita relação da atuação desse profissional com a educação em saúde. Para alguns autores, o enfermeiro é um educador por excelência e sua função na promoção de saúde e na prevenção de doenças é essencial ${ }^{17}$. Outros ainda reconhecem o potencial do profissional enfermeiro como coordenador de atividades de grupo e destacam as exigências metodológicas desses profissionais competentes para esse tipo de abordagem ${ }^{18,19}$.

Em suma, as práticas do profissional de saúdee da equipequeele molda epela qual é moldado determinam diferentes formas de visualizar as atividades de grupo e exercer esse tipo de assistência. Permitir a participação popular étambém uma forma de reorientar a proposta assistencial, na medida em que reconduz a globalidade das práticas ali exercidas, contribuindo para a superação do biologicismo, autoritarismo do doutor, desprezo pelas iniciativas dos usuários do sistema de saúde e enquadramento com soluções técnicas limitadas para problemas sociais gl obai $5^{20}$.

\section{Consideraçõesfinais}

Chega-se ao final das análises com a consciência do quão é relevante analisar determinados delineamentos da prática assistencial de modo que possam ser entendidos e ressignificados.

Dessemodo, tentou-se responder a uma pergunta, que, devido à prática não problematizada, não suscitava interesse para que fosse afinal desvelada: em que consistem as atividades degrupo na prática assistencial da rede básica de saúde? Ou melhor, em que consiste um dado procedimento, no qual 0 atendimento se processa por meio deum coletivo de pessoas reunidas, em um mesmo espaço de tempo e local, sob a responsabilidade de um profissional, ou trabalhador de saúde? Essa pergunta necessitava ser respondida de maneira sistematizada, pois a casuística desse tipo de procedimento se faz presente no cenário proposto como foco deste estudo.

Em relação ao perfil dos serviços em que as atividades de grupo estão acontecendo, é representativo o número de Unidades de Saúde da Família. Isso remete aos esforços das políticas públicas em saúde para reorientar o modelo assistencial e demonstra que há manifestação clara para deflagrar tal reorientação. Ainda que haja críticas em relação a esse formato operacional da assi stência básica de saúde, trata-se de uma forma de aproximar e horizontalizar as práticas de saúdee osseustrabalhadores da população. Identificam-setais intenções com os poten ciais resultados das atividades de grupo nesse âmbito.

Um outro aspecto que indica essas mudanças corresponde aos ajustes no processo de trabalho em saúde, de maneira que vem se constituindo inter ou, mais comumente, multidisciplinarmente. Condizente com essas tendências, os profissionais envolvidos com as atividades de grupo se organizam para exercer essa atividade também de maneira inter/multidisciplinar. $\mathrm{Ou}$ seja, a predominância, neste estudo, foi de que todos, ou a maioria dos integrantes das equipes de saúde, desenvolviam as atividades de grupo conjuntamente ou como coordenadores locais.

A partir desses achados e do fato de que $83 \%$ das unidades pesquisadas praticavam atividades de grupo, poder-se-ia dimensionar o potencial desse tipo de assistência no contexto analisado. Alguns dados, contudo, acrescentam questionamentos quanto à utilidade expressa pelos serviços e quanto à efetividade no que se refere ao caráter terapêutico. Tinha-seuma ideia prévia de que as atividades de grupo poderiam representar uma forma dos serviços para manejar a clientela excedente. Ou ainda, que essas práticas fossem deliberadas para determinados atendimentos em saúde. Isso pôde ser visualizado no caso das atividades atreladas a outras que compreendiam, por exemplo, medida de sinais vitais, entrega de medicações, avaliações individuais de saúde. Sabe-se que, por si só, não se tem elementos subsidiários para julgar negativamente essas práticas. 0 que se sabe é que, diante do cenário que se apresenta e que se quer transformar, a chance de implantar atividades ditas de educação em saúde com pretensões à modificação dos model os assistenciais é discutível.

0 próprio fato de haver a adoção significativa dessas atividades por parte dos serviços e dos profissionais ali atuantes já pode ser estimado como um acontecimento renovador da tipicida- 
de dos atos. Outros argumentos estão nas palavras dos entrevistados, os quais manifestaram interesse em promover e arranjar operacionalmente as disposições necessárias nos seus locais de trabalho para desenvolver atividades de grupo. Somam-se outras manifestações que remetem à questão da conveniência das atividades de grupo como momentos de excelência para exercer educação em saúde. Considera-se que édessa forma que se reflete, também, um outro foco de atenção, o que privilegia a promoção, a terapêutica, considerando os aspectos comunicacionais e relacionais (plural), que dão chances para 0 paciente se manifestar, explicitar suas vontadese intercambiar soluções que considera apropriadas conforme o seu próprio entendimento.

Dessa forma, a educação em saúde aparece como um direcionamento para consubstanciar a prática assistencial ea promoção da saúde. Esta pesquisa constatou que os grupos podem ser oportunos para o esclarecimento de informações sobre as doenças, para a troca de conhecimentos e experiências. A terapêutica é executada por meios não intervencionais e refere-se ao autocuidado e à proposta preventiva em relação às situações e agravos à saúde. Articulam-se 0 ambiente educativo proveniente do saber técnico ea informalidade do saber popular etem-seem funcionamento atividades que reelaboram as relações de trabalho, relação paciente-terapeuta e, com isso, reorientam, mesmo que pontualmente, o modelo assistencial vigente em saúde.

\section{Colaboradores}

R M affacciolli contribuiu para a produção dos dados contidos no artigo ena elaboração do texto. MJM Lopes contribuiu para a redação, orientação e revisão final do texto. 


\section{Referências}

1. M affacciolli R. Os grupos na atenção básica de saúde de Porto Alegre: usos e modos de intervenção terapêutica [dissertação]. Porto Alegre (RS): Escola de Enfermagem, Universidade Federal do Rio Grande do Sul; 2006.

2. Pichón-Rivière $E$, compilador. Diccionario de Términos y Conceptos de Psicología y Psicología Social. Buenos Aires: Nueva Visión; 2002.

3. Buss PM. Uma introdução ao conceito de promoção à saúde. In: Czeresnia $\mathrm{D}$, Freitas $\mathrm{CM}$, organizadores. Promoção da saúde: conceitos, reflexões e tendências. Rio de Janeiro: Fiocruz; 2003. p. 15-38.

4. Chiesa AM, Veríssimo MLOR. A educação em saúde na prática do PSF. Manual de Enfermagem. [site da Internet] [acessado 2004 nov 02]. Disponível em: http://www.ids-saude.org.br/enfermagem

5. Merhy EE. Engravidando palavras: o caso da integralidade. In: Pinheiro R, Mattos RD, organizadores. Construção social da demanda. Rio de Janeiro: Abrasco; 2005.

6. Brasil. Ministério da Saúde. Lei no 8.080 de 19 de setembro de 1990. Dispõe sobre as condições para a promoção, proteção e recuperação da saúde, a organização e o funcionamento dos serviços correspondentes e dá outras providências. Diário Oficial da União 1990; 20 set.

7. Brasil. M inistério da Saúde. Conselho Nacional de Saúde. 0 desenvolvimento do Sistema Único de Saúde: avanços, desafios e reafirmação dos seus princípios e diretrizes. Brasília: M inistério da Saúde; 2002.

8. Brasil. M inistério da Saúde. Programas. [site da Internet] [acessado 2006 abr 10]. Disponível em: http:/ /www.saude.gov.br

9. Zimerman DE. Fundamentos teóricos. In: Zimerman DE, Osório LC, organizadores. Como trabalhamos com grupos. Porto Alegre: Artes Médicas; 1997.

10. Bechelli LPC, Santos MA. Psicoterapia de grupo: como surgiu e evoluiu. Rev. Latino-Am. Enfermagem 2004; 12(2): 242-249.

11. Zimerman DE. Classificação geral dos grupos. In: Zimerman DE, Osório LC, organizadores. Como trabalhamos com grupos. Porto Alegre: Artes M édicas; 1997.
12. Pichón-Rivière $E$. 0 processo grupal. São Paulo: M artins Fontes; 1982.

13. Gayotto M LC, Domingues I. Liderança: aprenda a mudar em grupo. 3a ed. Petrópolis: Vozes; 1995.

14. Pinheiro R, Guizardi FL, Machado FRS, Gomes RS. Demanda em saúde e direito à saúde: liberdade ou necessidade? Algumas constituintes das práticas de integralidade. In: Pinheiro R, M attos RD, organizadores. Construção social da demanda. Rio de Janeiro: Abrasco; 2005.

15. Lopes MJM, Silva JLA. Estratégias metodológicas de educação e assistência na Atenção Básica de Saúde. Rev. Latino-Am. Enfermagem 2004; 12(4):683-688.

16. Machado MFAS, Monteiro EM LM ; Queiroz DT, Vieira NFC, Barroso M GT. Integralidade, formação de saúde, educação em saúde e as propostas do SUS: uma revisão conceitual. Cien Saude Colet 2007; 12(2):335-342.

17. Ramos DD, Lima MADS. 0 espaço de enfermagem em saúde coletiva na Rede Municipal de Saúde de Porto Alegre. Rev. Gaúcha Enferm 2000; 21(n. esp.) :45-55.

18. M unari DB, Fernandes CNS. Coordenar grupos: reflexão à luz das Diretrizes Curriculares $\mathrm{N}$ acionais do Curso de Graduação em Enfermagem. Rev. Gaúcha Enferm 2004; 25(1):26-32.

19. Munari DB, Rocha BS, Nunes DS, Medeiros M. 0 ensino da temática de grupo nos cursos de graduação em enfermagem no Brasil. Rev. Gaúcha Enferm 2005; 26(2):220-230.

20. Vasconcelos EM. Educação popular: de uma prática alternativa a uma estratégia de gestão participativa das políticas de saúde. Physis 2004; 14(1):67-83.

Artigo apresentado em 05/03/2008

Aprovado em 26/05/2008

Versão final apresentada em 06/08/2008 